\title{
Model Establishment of Whole Life Cycle for Energy Efficiency of Rural Residential Buildings in Northern China
}

\author{
Chenxia Suo ${ }^{1}$, Yong Yang ${ }^{1}$, Solvang Wei Deng ${ }^{2}$ \\ ${ }^{1}$ Beijing Institute of Petrochemical Technology, Beijing, China \\ ${ }^{2}$ Narvik University College, Narvik, Norway \\ Email: suochenxia@bipt.edu.cn, yangyonghebei@126.com,wds@hin.no \\ Received April 15, 2012; revised May 20, 2012; accepted May 30, 2012
}

\begin{abstract}
The building energy efficiency is determined by the climatic region and the energy-saving measures. In this paper an assessment model for energy efficiency of the rural residential buildings in the northern China was established by the method of whole life cycle. The energy consumption of the rural residential buildings in different stages was analyzed through quantitative method in this model. At the same time, the corresponding energy efficiency assessment system was developed.
\end{abstract}

Keywords: Building Energy Efficiency; Whole Life Cycle; Assessment System

\section{Introduction}

The energy efficiency assessment of buildings in their whole life cycles is used for analyzing the energy consumption of buildings and realizing overall consideration of the energy consumptions of building projects based on a whole life cycle theory, mainly including the energy consumptions of building materials in their manufacturing and transportation and the energy consumptions of building projects in their construction, operation, dismantling and recycling.

\section{Principles of the Establishment of the Assessment Model}

1) Scientific principle: The design of the post assessment indicator system of building energy efficiency process should fully consider the characteristics of building energy efficiency.

2) Overall principle: The design of the indicators used in the energy efficiency assessment of buildings in their whole life cycles should reflect the energy efficiency performance.

3) Practical principle: In the design of the indicator system of the energy efficiency assessment of a building in its whole life cycle, the principle of practicability should be followed, the accuracy and availability of data

*Beijing Energy Management Evaluation \& Innovation Team (PHR 201007136); The Ministry of Education of Philosophy and Social Science Planning Project (10YJA630139). should be considered and targeted indicators that can reflect the building project comprehensively and are mutually independent should be selected in the light of the purpose of the study and the characteristics of the object of study.

4) System integrity principle: The establishment of the indicators for environment friendly buildings is a complex systematic work that must reflect the buildings' economic characteristic and other basic characteristics regarding resources, energy sources and indoor environmental quality.

\section{Influencing Factors}

In order to ensure its practicability, an assessment model should reflect the characteristics of the assessed building. Thus, an assessment model is influenced by factors like the regional factor, the economic development level, the local customs and so on.

\subsection{Scope and Climate Features of the Regions Needing Heating in the Northern China}

1) In the regions needing heating in the northern China, the winters are long, cold and dry; both the annual temperature range and the daily temperature range are large; the days with an average daily temperature equal to or lower than $5^{\circ} \mathrm{C}$ account for 25 to 40 percent of the total days of a year and the days with a maximum temperature equal to or higher than $35^{\circ} \mathrm{C}$ account for 22 percent of total days of a year. 
2) The regions needing heating in the northern China are usually drouthy and rainless regions. In these regions, the annual average relative humidity is 50 to 70 percent; the annual number of rainy days is 60 to 100 days; the annual precipitation is $300 \mathrm{~mm}$ to $1000 \mathrm{~mm}$; the daily maximum precipitation is $200 \mathrm{~mm}$ to $300 \mathrm{~mm}$ for most of places or over $500 \mathrm{~mm}$ for some places; and the annual number of snowy days is less than 15 days.

3) The regions needing heating in the northern China has strong solar radiation: The annual solar radiation intensity is $150 \mathrm{~W} / \mathrm{m}^{2}$ to $190 \mathrm{~W} / \mathrm{m}^{2}$; the annual sunshine duration is $2000 \mathrm{~h}$ to $2800 \mathrm{~h}$; and the annual percentage of sunshine is 40 to 60 percent [1].

\subsection{Life Behavior Characteristics of the Peasants in the Northern China}

1) The activities of the peasants in the northern China mainly happen on heated brick beds. The peasants have meals, study, do housework, receive visitors and sleep on heated brick beds, so they have special furniture different from the furniture used in cities, including short-legged table and stools for used on heated brick beds.

2) The peasants in the northern China have the habits of paying visits to their relatives and friends and doing some activities in front of or behind their houses, so the interiors of their houses have frequent ventilation. In their opinions, they will be easy to catch cold if the indoor temperatures of their houses are too high. Based on the analyses above, it is suggested to make the indoor calculating temperature $16^{\circ} \mathrm{C}$ in the thermal performance design and energy efficiency design [2].

\subsection{Characteristics of the Rural Residential Buildings in the Northern China}

The rural residential buildings in the severe cold region is limited by the production and life behaviors and living patterns of the peasants there. the residential buildings mainly have a brick-concrete structure or a brick-wood structure and these two kinds of structures account for about 71.64 percent in all the structures; the severe cold region has 95,054,900 permanent resident households that account for 46.48 percent of the total permanent resident households of the country, with a total heating area that is 39 percent of the total area of the rural residential buildings of the country.

\subsection{Characteristics of the Heating of the Residential Buildings of the Peasants in the Northern China}

Viewed from the heating facilities, the heated brick beds (also called kangs for short) and suspended kangs (also called adobe kangs) used a lot in the rural areas in the northern China are common heating equipment in the residential buildings in the northern China. Suspended kangs are based on a new type of kang-linked stoves that are seasonally designed in the light of the scientific principles of combustion and heat transfer. Viewed from the form of heating, heating may be combined with cooking or separated from cooking. In the form of heating combined with cooking, heating in winter is combined with cooking, i.e. heating can be realized at the same time of cooking. The heating separated from cooking means that heating is separated from cooking [2].

\subsection{Characteristics of the Materials of the Residential Buildings of the Peasants in the Northern China}

Most of the building materials are locally obtained. Their houses have a brick-concrete structure and a brick-wood structure.

1) In a brick-concrete structure, the vertical loadbearing walls and posts of buildings are made of bricks or blocks and the transverse load-bearing beams, floorslabs and roof panels have a reinforced concrete structure. In other words, a brick-concrete structure is a structure with a minority of parts made of reinforced concrete and a majority of parts made of brick walls for load bearing.

2) In a brick-wood structure that is a kind of architecttural structure, the vertical load-bearing walls and posts of buildings are made of bricks or blocks and floorslabs and roof frames are made of wood. Due to the restricttions of mechanics engineering and engineering strength, a building with a brick-wood structure usually has one to three storeys [3].

\section{Energy Efficiency Assessment System}

\subsection{Determination of Assessment Indicators}

According to the function goal and hierarchical assessment indicator system structure of the energy efficiency assessment system of rural buildings in their whole life cycles, this paper has done level-by-level analysis and decomposition of the structure and logic level relationship of the assessment of energy-efficient residential buildings, determined the mutual subordinate relationships of the factors and established a hierarchical assessment system for the assessment model for the energy efficiency of the rural buildings in the regions needing heating in the northern China.

Overall indicator layer A: Overall goal of the energy consumption assessment of the rural buildings in their whole life cycles.

Classified indicator layer B: The compositions of the energy consumption assessment of the rural buildings in 
their whole life cycles.

Sub-classified indicator layer C: The classified indicators are made more detailed in this layer. The assessment content factors of the sub-classified indicators are more detailed contents and explanations of the classified indicators (See Table 1). The indicator system structure of the energy efficiency assessment system of rural buildings is as shown in Table 1 and Figure 1.

\subsection{Grade Standard of the Assessment Result}

Grade standard is a quantitative standard for rating of Excellent, Good, Fair, Pass and Rejected. In an energy-efficient building assessment indicator system, dif- ferent indicators have different dimensions, meanings and forms of expression. The grade standard is then determined based on the total score. The grade standard is as shown in Table 2.

\subsection{Calculation of Building Energy Consumption}

The energy efficiency assessment of buildings in their whole life cycles mainly include the assessment of the energy consumptions in five stages, including the manufacturing of building materials, the transportation of building materials, the construction of building projects, the operation of building projects and the dismantling

Table 1. Indicators for the energy efficiency assessment of the rural buildings in their whole life cycles.

\begin{tabular}{|c|c|c|c|}
\hline \multirow{2}{*}{ Overall indicator A } & \multirow{2}{*}{ Classified indicator $\mathbf{B}$} & \multicolumn{2}{|c|}{ Sub-classified indicator $\mathrm{C}$} \\
\hline & & Assessment indicator & Explanation of assessment indicator \\
\hline \multirow{10}{*}{$\begin{array}{l}\text { Energy consumption } \\
\text { assessment system of } \\
\text { buildings in their } \\
\text { whole life cycles (A) }\end{array}$} & \multirow{2}{*}{$\begin{array}{l}\text { Energy consumption in } \\
\text { manufacturing of building } \\
\text { materials (B1) }\end{array}$} & $\begin{array}{l}\text { Unit energy consumption of } \\
\text { building materials (C11) }\end{array}$ & $\begin{array}{l}\text { Calculate the energy consumptions in the } \\
\text { exploration and manufacturing of different building } \\
\text { materials. }\end{array}$ \\
\hline & & $\begin{array}{l}\text { Consumption of building } \\
\text { materials (C12) }\end{array}$ & Calculate the consumption of each building material. \\
\hline & \multirow{2}{*}{$\begin{array}{l}\text { Energy consumption in } \\
\text { transportation of building } \\
\text { materials (B2) }\end{array}$} & $\begin{array}{l}\text { Energy consumption of unit } \\
\text { mileage in transportation }(\mathrm{C} 21)\end{array}$ & $\begin{array}{l}\text { Calculate the energy consumption of unit mileage } \\
\text { based on different modes of transportation. }\end{array}$ \\
\hline & & Distance of transportation (C22) & The total mileage of each mode of transportation \\
\hline & \multirow[b]{2}{*}{$\begin{array}{l}\text { Energy consumption in } \\
\text { construction of building } \\
\text { projects (B3) }\end{array}$} & $\begin{array}{l}\text { Energy consumption in the use of } \\
\text { building equipment (C31) }\end{array}$ & $\begin{array}{l}\text { Sum up the power energy sources, rated powers and } \\
\text { machine-teams of the main building machinery. }\end{array}$ \\
\hline & & $\begin{array}{l}\text { Energy consumption in the } \\
\text { management of building projects } \\
\text { (C32) }\end{array}$ & $\begin{array}{l}\text { The energy consumptions of other aspects except for } \\
\text { main building machinery, e.g. the energy } \\
\text { consumptions of construction quality, construction } \\
\text { management, etc. }\end{array}$ \\
\hline & \multirow[t]{2}{*}{$\begin{array}{l}\text { Energy consumption in } \\
\text { operation of building } \\
\text { projects (B4) }\end{array}$} & $\begin{array}{l}\text { Operation energy consumption of } \\
\text { unit area }(\mathrm{C} 41)\end{array}$ & $\begin{array}{l}\text { It refers to the standard coal consumed by unit } \\
\text { building are in a heating period to keep the indoor } \\
\text { calculating temperature under the average outdoor } \\
\text { temperature in the heating period. }\end{array}$ \\
\hline & & Total building area (C42) & Total building area of a building \\
\hline & \multirow[b]{2}{*}{$\begin{array}{l}\text { Energy consumption in } \\
\text { dismantling and recycling } \\
\text { (B5) }\end{array}$} & $\begin{array}{l}\text { Energy consumption in } \\
\text { equipment dismantling (C51) }\end{array}$ & $\begin{array}{l}\text { Sum up the power energy sources, rated powers and } \\
\text { machine-teams of the main dismantling machinery. }\end{array}$ \\
\hline & & $\begin{array}{l}\text { Recycling and re-manufacturing } \\
\text { energy consumption of building } \\
\text { materials (C52) }\end{array}$ & $\begin{array}{l}\text { Recycled and reuse broken concrete steel, } \\
\text { reinforcement, glass and concrete and bury other } \\
\text { wastes and the energy saved by the recycling and } \\
\text { reuse compared with the use of completely new } \\
\text { building materials. }\end{array}$ \\
\hline
\end{tabular}

Table 2. Grade of the result of the building energy consumption assessment.

\begin{tabular}{ccc}
\hline Grade & Score of the assessment & Energy-saving effect \\
\hline Excellent & $1-0.8$ & The energy-saving effect is national leading. \\
Good & $0.8-0.6$ & The expected energy-saving effect is realized and the actual energy-saving effect is very obvious. \\
Pass & $0.6-0.4$ & The expected energy-saving effect is realized. \\
Rejected & Lower than 0.4 & The expected energy-saving effect is not realized. \\
\hline
\end{tabular}




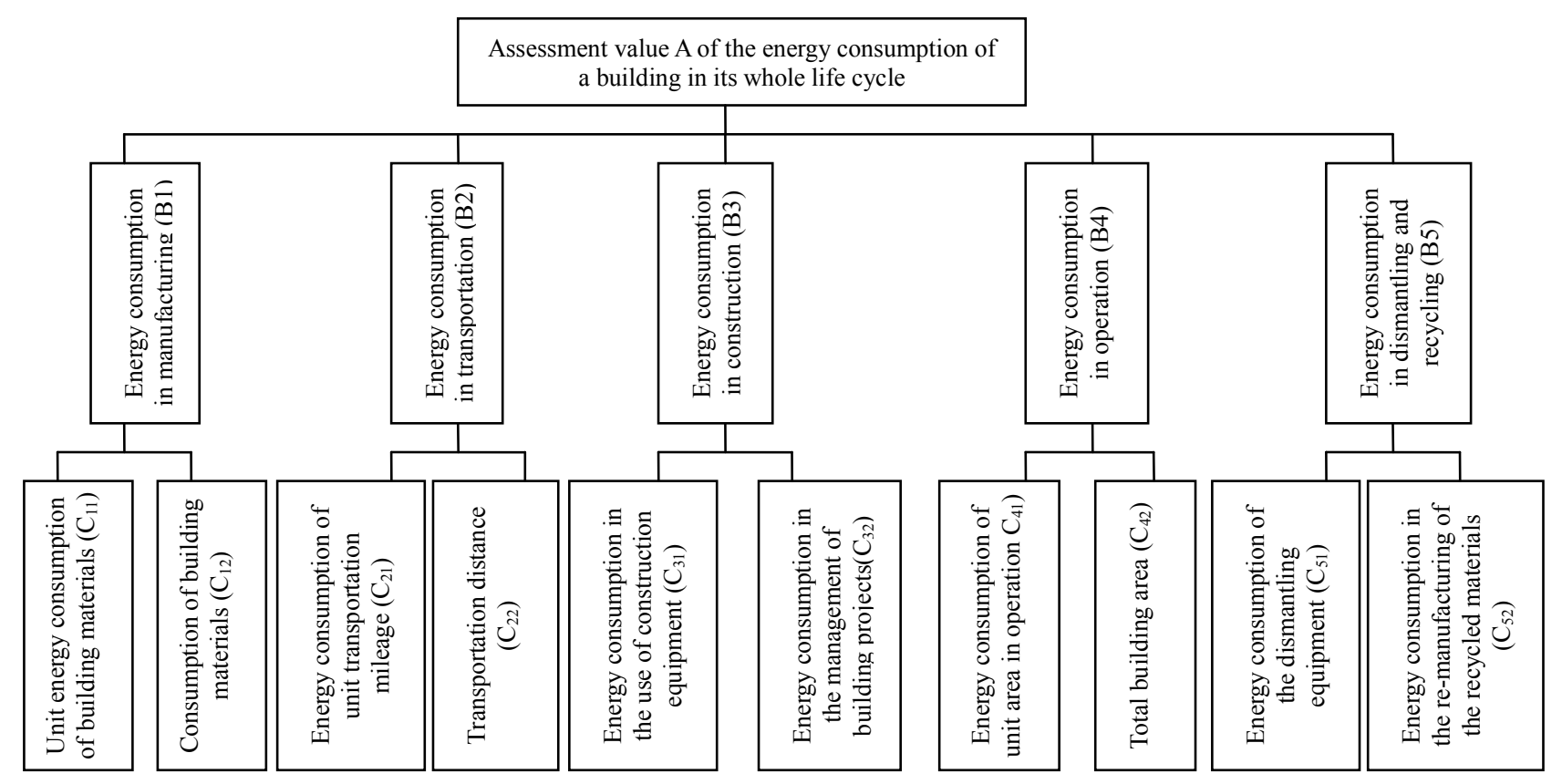

Figure 1. Assessment model for the energy efficiency of the rural residential buildings in the northern china in their whole life cycles.

and recycling of building projects [4].

$$
\mathrm{E}_{\text {tot }}=\mathrm{E}_{\text {manu }}+\mathrm{E}_{\text {erect }}+\mathrm{E}_{\text {occup }}+\mathrm{E}_{\mathrm{demo}}+\mathrm{E}_{\mathrm{dis}}
$$

In the formula:

$E_{\text {tot }}$ refers to the total energy consumption of the buildings in their whole life cycles (unit: KJ);

$\mathrm{E}_{\text {manu }}$ refers to the energy consumption in the manufacturing of building materials (unit: KJ);

$\mathrm{E}_{\text {erect }}$ refers to the energy consumption in the transportation of building materials (unit: $\mathrm{KJ}$ );

$\mathrm{E}_{\text {occup }}$ refers to the energy consumption in the construction of building projects (unit: $\mathrm{KJ}$ );

$\mathrm{E}_{\mathrm{dem}}$ refers to the energy consumption in the operation of building projects (unit: $\mathrm{KJ}$ ); and

$\mathrm{E}_{\mathrm{dis}}$ refers to the energy consumption in the dismantling and recycling of building projects (unit: $\mathrm{KJ}$ ).

Hereunder are the calculation formulas for the energy consumptions in different stages.

1) Energy consumption in the manufacturing of building materials

$$
\mathrm{E}_{\text {manu }}=\mathrm{E}_{\text {manu }}, p_{\text {rod }}+\mathrm{E}_{\text {manu }}, \mathrm{r}_{\text {enow }}
$$

$\mathrm{E}_{\mathrm{manu}}, p_{\mathrm{rod}}=\sum_{i=1}^{n} a_{i} *(1+P) * A_{i}$

$\mathrm{E}_{\text {manu }}$ refers to the total energy consumption of building materials in the manufacturing stage (unit: $\mathrm{KJ}$ );

$\mathrm{E}_{\text {manu, }}, p_{\text {rod }}$ refers to the total energy consumption in the manufacturing of the building materials used in the construction of buildings (unit: KJ);

$n$ refers to the number of the types of the building materials used for buildings;

$a_{i}$ refers to the consumption of building material $i$ and is usually expressed in weight (Ton or $\mathrm{Kg}$ ) or volume $\left(\mathrm{m}_{3}\right)$;

$p$ refers to the ratio of the building material $i$ abandoned in construction and is expressed in percentage (\%); and

$A_{i}$ refers to the unit energy consumption in the manufacturing of building material $i$ (unit: $\mathrm{KJ}$ ).

Different kinds of building materials have different service lives, so the energy consumption of building materials of building projects needs to be calculated repeatedly according to the service lives of building materials.

$$
\mathrm{E}_{\mathrm{manu}}, \mathrm{r}_{\text {enow }}=\mathrm{E}_{\mathrm{manu}}+p_{\text {rod }} *\left[\frac{Y_{\text {bui }}}{Y_{\text {mat }}}-1\right]
$$

$E_{\text {manu }}, r_{\text {enow }}$ refers to the energy consumption in the manufacturing of the material buildings used for refurbishing buildings (unit: $\mathrm{KJ}$ );

$Y_{b u i}$ refers to the service life of a building (mainly the service life of the main structure of the building) (unit: year); and

$Y_{\text {mat }}$ refers to the service lives of various building materials (unit: year).

2) Energy consumption in the transportation of building materials

The energy consumption in the transportation of building materials used in construction in building projects may be calculated based on the consumptions, transportation distances and unit transportation energy consumption of building materials of the buildings. If calculated based on the types and transportation distances 
of building materials, calculation may be done through the formula below.

$$
\mathrm{E}_{\text {trans }}=\sum_{i=1}^{n} a_{i} *(1+P) B_{i} * A_{i}
$$

In the formula:

$n$ refers to the types of the building materials used for buildings;

$a_{i}$ refers to the consumption of building material $i$ and is usually expressed in weight (Ton or $\mathrm{Kg}$ ) or volume (m3);

$p$ refers to the percentage of the building materials abandoned in construction;

$B_{i}$ refers to the unit energy consumption of building materials transported in different means (unit: $\mathrm{MJT} / \cdot \mathrm{K} / n$ ).

$C_{i}$ refers to the transportation distance.

3) Energy consumption in the construction of building projects

The energy consumption in the transportation of building materials differs with the specific transportation means. If the building materials are basically local ones, the transportation means will be basically the same and the main factor affecting the energy consumptions are the transportation distances of the building materials.

$$
\mathrm{E}_{\text {erect }}=\sum_{i=1}^{n} m * a_{i} * p_{i}
$$

$n$ refers to the number of the types of the construction methods used;

$m_{i}$ refers to the unit construction area $\left(\mathrm{m}_{2}\right)$, weight (Ton) or volume $\left(\mathrm{m}_{3}\right)$ of each construction method; and

$p_{i}$ refers to the unit energy consumption of the construction method (unit: KJ).

4) Energy consumption in the operation of building projects

For an ordinary reinforced concrete building, the total energy consumption in its service stage used accounts for about 70 to 80 percent of its whole life cycle. Even for a most energy-efficient building at present, the total energy consumption in its service stage accounts for 50 to 60 percent. The total energy consumption in the service stage of a building includes the energy consumed by air-conditioning, heating, water heating, cooking, lighting, electrical equipment [6].

$$
\begin{aligned}
\mathrm{E}_{\text {occup }} & =\mathrm{E}_{\text {occup, heat }}+\mathrm{E}_{\text {occup, vent }}+\mathrm{E}_{\text {occup, light }} \\
& +\mathrm{E}_{\text {occup, sub }}
\end{aligned}
$$

$E_{\text {occup,heat }}$ refers to the energy consumption of the air-conditioning system (unit: $\mathrm{KJ}$ );

$\mathrm{E}_{\text {occup,vent }}$ refers to the energy consumption of the ventilation system (unit: $\mathrm{KJ}$ );

$\mathrm{E}_{\text {occup,light }}$ refers to the energy consumption of the lighting system (unit: $\mathrm{KJ}$ ); and

$\mathrm{E}_{\text {occup,sub }}$ refers to the energy consumption of the auxiliary systems (unit: $\mathrm{KJ}$ ).

5) Energy consumption in the dismantling and recy- cling of building projects

The energy consumption in this stage includes the energy consumption in dismantling and energy consumption in the transportation of covering soil and filling materials. The energy consumption in dismantling is regarded as 90 percent of the energy consumption in construction and the energy consumption in the transportation of covering soil and filling materials is calculated based on the construction area, the average soil covering and material filling, the average specific gravities of the covering soil and filling materials and the average transportation distance [5].

Waste and old building materials include recyclable ones and unrecyclable ones. Generally speaking, glass, wood, aluminum material, steel material and other building materials are recyclable.

$$
\begin{gathered}
\mathrm{E}_{\mathrm{dis}}=\mathrm{E}_{\mathrm{dis}, \text { demo }}-\mathrm{E}_{\mathrm{dis}, \text { recycle }}+\mathrm{E}_{\mathrm{dis} \text {, unrecycle }} \\
\mathrm{E}_{\mathrm{dis}, \text { demo }}=0.9 * \mathrm{E}_{\text {erect }}+\mathrm{M} * 1.5 * 2 * 1.836 \\
\mathrm{E}_{\mathrm{dis}, \text { recycle }}=\sum_{i=1}^{n} a_{i} * q_{i} * A_{i}
\end{gathered}
$$

$E_{\text {dis, demo }}$ refers to the energy consumption in the dismantling stage (unit: $\mathrm{KJ}$ );

$\mathrm{E}_{\mathrm{dis} \text {, recycle }}$ refers to the energy consumption in the recycling of building materials;

$E_{\text {dis, unrecycle }}$ refers to the energy consumption in the disposal of building wastes;

$E_{\text {erect }}$ refers to the total energy consumption in the construction stage (unit: KJ);

$\mathrm{M}$ refers to the construction area needing soil covering and material filling after the dismantling stage; and $q$ refers to the recycling rate of building materials.

\section{Assessment Model for Energy Efficiency of the Rural Residential Buildings in Northern China in Their Whole Life Cycles}

Based on a full life cycle theory and an AHP, this paper establishes an assessment model for the energy efficiency of the rural residential buildings in the northern China in their whole life cycles.

1) Establishment of a hierarchical model

2) Establishment of a judgment matrix

The judgment matrix of the indicators on the first layer is a comparison matrix of the importance of the five indicators under the dominance of the overall goal assessment value A of the energy consumption of a building in its whole life cycle. The grade standard of judgment matrix is as shown in Table 3.

3) Determination of the weights of the judgment matrix

Determination of weights: It is realized through interview with experts. Several experts are invited to fill out a consultation form to form a judgment matrix between the 
Table 3. Sadi scale for multiple comparison.

\begin{tabular}{|c|c|}
\hline Scale & Meaning \\
\hline 1 & Two factors have the equal importance. \\
\hline 3 & $\begin{array}{l}\text { The former factor is slightly more important } \\
\text { than the latter one. }\end{array}$ \\
\hline 5 & $\begin{array}{l}\text { The former factor is obviously more } \\
\text { important than the latter one. }\end{array}$ \\
\hline 7 & $\begin{array}{l}\text { The former factor is very important } \\
\text { compared with the latter one. }\end{array}$ \\
\hline 9 & $\begin{array}{l}\text { The former factor is extremely important } \\
\text { compared with the latter one. }\end{array}$ \\
\hline $2,4,6,8$ & $\begin{array}{l}\text { The means of the judgments above in } \\
\text { comparison of two factors }\end{array}$ \\
\hline $\begin{array}{l}\text { Reciprocals of the } \\
\text { figures above }\end{array}$ & $\begin{array}{l}\text { The results above when the order of } \\
\text { comparison above it opposite. }\end{array}$ \\
\hline
\end{tabular}

factor layer and the assessment value $A$ of the energy consumption of a building in its whole life cycle.

4) Consistency check

The process of doing a multiple comparison between the factors of a layer and the factors of the higher layer to obtain the weights of the indicators of the lower layer is called single hierarchical sequencing.

$$
\begin{gathered}
C R=\frac{C I}{R I} \\
C I=\frac{\lambda_{\text {max }}-n}{n-1}
\end{gathered}
$$

$R I$ refers to the average random consistency indicator;

$C I$ refers to the consistency indicator;

$\lambda_{\max }$ refers to the maximum of the characteristic equation; and $\mathrm{n}$ refers to the order of the judgment matrix.

5) General hierarchical sequencing and its consistency check

In the process, on the basis of the relative weights of the sub-systems, the weights of the factors on the last layer are multiplied by the relative weights of the controlled factors on the higher layer in turn to form the absolute weights of the factors for the overall goal.

$$
C R=\frac{\sum_{i=1}^{n} B_{i} C I_{i}}{\sum_{i=1}^{n} B_{i} R I_{i}}
$$

If the $C R$ is smaller than 0.1 , it will be regarded that the general hierarchical sequencing has satisfying consistency.

Supposing the weights of the indicators of the indicator layer obtained through the AHP are $w_{1}, w_{2}$ and so on (ending with $w_{n}$ ) and the indicator values obtained after dimensionless processing are $r_{1}, r_{2}$ and so on (ending with $r_{n}$ ), then the economic indicator $A$ of an environment friendly building will be obtained through the formula below:

$$
\begin{gathered}
A=r * w^{T} \\
r=\left(r_{1}, r_{2}, \cdots, r_{n}\right) \\
w^{T}=\left(w_{1}, w_{2}, \cdots, w_{n}\right)
\end{gathered}
$$

\section{Application of the Assessment Model}

1) From the application of the model in the energysaving reconstruction project of the residential $b$ total energy consumption of other aspects took a small proportion (less than 1 percent) in the total energy consumption of the building project. In a word, the operation stage of the buildings is key for the energy efficiency of the buildings, and, after the reconstruction, the proportion of the energy consumption in operation of the buildings was decreased while that of the energy consumption in construction was increased.

2) With the increase of the service lives of the buildings, the energy consumption in the operation of the buildings keeps increasingly. The energy consumption in the operation of the buildings after the reconstruction is lower than that before the reconstruction and the energy consumption in the construction of the buildings after the reconstruction is higher than that before the reconstruction, so the total energy consumption of the buildings after the reconstruction will be increasingly lower than that before the reconstruction and the energy-saving effect of the buildings will be more and more obvious with time on.

3) Viewed from the total energy consumption, the buildings have shown an obvious reconstruction effect: The reconstruction of the single buildings has resulted in an energy consumption reduction of $11,620,037 \mathrm{Kj}$ or 24.31 percent. Furthermore, the energy-saving effect is more and more obvious with increase of the building area.

4) Viewed from overall assessment, the grade of the assessment result is "Pass" before the reconstruction and "Good" after the reconstruction, i.e. the grade of the assessment result has been improved obviously.

\section{REFERENCES}

[1] W.-H. Tsai, S.-J. Lin, J.-Y. Liu, W.-R. Lin and K.-C. Lee, "Incorporating Life Cycle Assessments into Building Project Decision-Making: An Energy Consumption and CO2 Emission Perspective," Energy, Vol. 36, No. 5, 2011, pp. 3022-3029. doi:10.1016/j.energy.2011.02.046

[2] C. Y. Zhang, C. X. Suo and D. S. Wei, "Application of Energy-Saving Technologies in the Rural Buildings in China and Its Benefit Assessment," Economic Science 
Press, Beijing, 2010

[3] O. Bozdag and M. Secer, "Energy Consumption of RC Buildings during Their Life Cycle," Sustainable Construction, Materials and Practices: Challenge of the Industry for the New Millennium, Minho, 12-14 September 2007, pp. 480-487.

[4] L. Uzsilaityte and V. Martinaitis, "Impact of the Implementation of Energy Saving Measures on the Life Cycle
Energy Consumption of the Building," 7th International Conference Environmental Engineering, Vol. 1-3, 2008, pp. 875-881,

[5] Japan Sustainable Building Consortium, "Comprehensive Assessment System for Building Environmental Efficiency-Green Design Tool," China Architecture \& Building Press, Beijing, 2005. 